\title{
The Effect of Interactive Drills Using Dry Lab on the Acquisition of Laboratory Skills in Learning Science Among the Ninth-Grade Female Students in Palestine in Light of Their Thinking Style
}

\author{
Areej Al Muhtasib ${ }^{1}$ \\ ${ }^{1}$ PhD Philosophy of Curriculum and Teaching Methods, University of Jordan, Jordan \\ Corresponding: Areej Al Muhtasib, PhD Philosophy of Curriculum and Teaching Methods, University of Jordan, \\ Jordan. Palestine - Hebron. E-mail: x-areej10@hotmail.com
}

Received: July 1, 2019

Accepted: July 26, 2019 Online Published: September 19, 2019

doi:10.5539/jel.v8n5p89

URL: https://doi.org/10.5539/jel.v8n5p89

\begin{abstract}
The study aimed to identify the effect of the interactive drills using the dry laboratory on the acquisition of scientific concepts and laboratory skills in science among the ninth-grade female students in Palestine in light of their thinking styles. The study used quizzes of experimental method. The sample consisted of 68 female students distributed on two groups: an experimental group $(\mathrm{n}=34$ students $)$ and a control group $(\mathrm{n}=34$ students). In order to achieve the objectives of the study, test of laboratory skills and thinking styles tests were used. The results showed that there were statistically significant differences between the means of the experimental group that was studied using the interactive method of the dry laboratory and the control group that studied using the traditional method via laboratory skills tests in favor of the experimental group. The results also revealed that there was an interaction between the method of teaching (the interactive drills using dry laboratory and the traditional method) and thinking styles on the acquisition of laboratory skills. In light of these results, several recommendations were suggested.
\end{abstract}

Keywords: interactive training, dry laboratory, laboratory skills thinking style

\section{Introduction}

Rapid technological developments encompassing all aspects of life are the dominant feature of the present era. Examples of these aspects are teaching methods that help students to achieve one of the most important objectives of the educational process which is to master different concepts and skills, including in particular scientific concepts. However, traditional methods predominate over teaching methods used by science teachers, which are based on teaching so that the student is only a listener. Although these traditional methods of overcrowded classrooms are suitable for students, and theoretical examinations are made, making the teacher's work easy, it is difficult to follow students' progress individually or measure their individual skills. Despite the appropriateness of these traditional methods for overcrowded classrooms and theoretical examinations, which makes teacher work easy, it is difficult to follow students' progress individually or measure their individual skills.

Depending on the importance of science and its direct link with the student's life, officials of the educational process pay great attention to science in terms of curricula and teaching methods, so that students receive science in a functional way to enable them to apply in life (Aram, 2012). The importance of laboratory work, which links theoretical and scientific aspects and the development of different skills among students is highlighted here. Education scientists, in the light of modern trends in teacher training, have called for the need for teachers to acquire competencies related to laboratories and practical activities, because of the benefits provided by the laboratory to students, including: acquiring manual and educational skills, such as recording and collecting data, writing reports, acquiring basic science skills, self-learning, as well as shaping student scientific attitudes and tendencies (Al-Soub, 2007).

In addition, the laboratory plays an active role in developing students' scientific curiosity, improving their ability to solve problems, development of thinking patterns and scientific skills such as the use of laboratory devices and the conduct of various laboratory processes. In order to equip students with such skills, it is necessary to provide opportunities for students to practice laboratory work under the supervision of teachers (Ali, Zakaria, \& 
Sleem, 2010).

This shows the need to equip the science teacher with the laboratory skills he needs to perform his tasks effectively (Al-Hodabi \& Al-Mokhlafi, 2009).

Thinking is one of the important topics in cognitive psychology. It is one of abstract concepts, such as intelligence, that is difficult to measure directly. Therefore, researchers used different names to distinguish between patterns of thinking, while emphasizing its complexity. Examples include talking about critical, conceptual, creative, cognitive, mathematical, and other types of thinking. Thinking patterns are seen as a continuum line, beginning with simple thinking and ending with advanced thinking such as convergent /divergent thinking, abstract /contemplative thought, critical/creative thinking (Al-Shurideh \& Bisharah, 2010).

Thinking is a purposeful evolutionary behavior that takes place in certain situations, it is a relative concept, since one cannot reach all kinds of thinking or reach the stage of perfection in thinking (Attiyat, 2013). The style of thinking of an individual is the way in which he or she receives knowledge and experience, and in the way knowledge is organized, recorded, encoded, preserved, and retrieved, either by means of a concrete, semi-visual, or symbolic means by letter, word or number. Hence, thinking is one of the basic determinants of an individual's behavior and has an important influence on the formulation of this behavior. The thinking disorder of an individual is reflected in his or her behavior and appears in his activities and actions (Al-Tarawneh \& Al-Qudah, 2014).

Educational goals emphasize the development of thinking among generations, since higher levels of thinking do not grow by age but by training and practice, and success in life requires high intellectual abilities (Jamal \& Al-Hawidi, 2003). Methods of teaching science in the laboratory vary, including the method of basic scientific presentation, which is one of the effective methods of teaching science, especially when teaching basic scientific concepts and principles, since starting a lesson using method is a good input to attract the attention of students, which is a good way to get rid of routine during class. This type of teaching is centered around the teacher who uses the tools in front of students. However, the experienced teacher exploits the good work presentation in order to explore the information, so as to stimulate the processes of thinking and skills development such as observation, analysis and evaluation (Al-Bashyreh \& Al-Obeydeen, 2014).

\subsection{Problem Statement and Questions}

Students suffer from poor acquisition of laboratory skills in various scientific subjects, including science. The results of the Student Achievement Study in Science and Mathematics (Timss) in the world (2011) confirmed this result. This is due to several factors, including: the use of normal methods of presenting scientific content, lack of potential, teachers' dependence on indoctrination rather than scientific activities and mental activities (Zeitoun, 2007). According to the 15th annual report issued by the Palestinian Central Bureau of Statistics, "Children of Palestine: Issues and Statistics", the percentage of public schools with a special room for the scientific laboratory is $68 \%, 48.2 \%$ in UNRWA schools and 50.6\% in private schools (Palestinian Central Bureau of Statistics, 2011). Based on the role of scientific laboratories and their importance in facilitating the study of science and activating the process of teaching, it is found that there is a rare use of laboratories in conducting scientific experiments related to the science. Due to the limited availability of well-equipped scientific laboratories in most schools in Palestine (Dar Ibrahim, 2014). Since the curriculum is full of scientific educational experiences, which are an obstacle for teachers to use the science lab, and the lack of sufficient time for teachers to carry out practical activities in laboratories, the teaching of science in Palestine is theoretically away from experimentation. Therefore, the researchers sought to use the method of interactive drills in the dry laboratory, which may contribute to improve the ability of students to acquire laboratory skills, so the problem of the study is to answer the following questions:

1) Does the acquisition of laboratory skills by ninth grade female students differ substantially according to the method of teaching (interactive drills in the dry laboratory or in the traditional method)?

2) Is there an effect of the interaction between the method of teaching (interactive drills using the dry laboratory and the traditional method) and styles of thinking (concrete and abstract) in the acquisition of laboratory skills in the science of the ninth-grade female students?

\subsection{Study Importance}

The dry lab is a fundamental part of the training and teaching program of science due to its many advantages that help in discovery, its importance in teaching science, preparing the teacher of science. The importance of study can be described through the following two aspects:

1.2.1 Theoretical Importance: It is hoped that this study helps teachers to rely on themselves to design interactive educational programs. Moreover, the results of the study may benefit all teachers and specialists in using dry laboratory to improve the effectiveness of the educational process. The study also helps researchers to design 
educational and training programs, and to study other skills and fields.

1.2.2 Practical Importance: The practical importance of this study is that it demonstrates the operational application of interactive drills using the dry laboratory, which is used by the teacher to help students acquire laboratory skills, and to uncover styles of thinking, and design programs to train in-service teachers to use interactive drills such as smart board, computer and others. As well as the development of a scientific material for science teachers using interactive training programs, which may contribute to raising the level of education in Palestine.

\subsection{Theoretical and Operational Terms}

1.3.1 Interactive Drills: learning programs oriented to learners who have already learned the concept or the skill, provide a series of examples to increase his or her proficiency in the use of the skill. Examples of interactive drills include dry lab, smart board, and interactive video (Al-Najdi, Abed Al-Hadi, \& Rashed, 2002). Operationally, interactive drills refer to educational programs that contain an explanation of science lessons in the ninth-grade curriculum, as well a set of drills that help to use the dry laboratory, and provides feedback directly to each student.

1.3.2 Dry Lab: Using computer software such as Crocodile Mathematics, ICT, Chemistry, Physics that enable students to carry out scientific activities and conduct activities and conduct experiments through interaction with the computer, so that the teacher will provide the education clearly, and give the students the opportunity to learn for themselves (Salah Abdul Mohsen Ajaj Educational Blog, 2014). It is defined in operational terms as the use of computer software to carry out the activities and experiments found in Module 4 (Elements and Chemical Interactions in our Lives) in the ninth-grade science book, which is scheduled by the Ministry of Education in Palestine for the academic year 2017/2018.

1.3.3 Laboratory Skills: A range of activities performed by the student includes a consistent use of a small or large group of muscles of the body, and movement of the body is the predominant feature (Al-Hodabi \& Al-Mukhlafi, 2009). It is defined as the degree to which the student obtains each type of thinking from the list of patterns of thinking (concrete and abstract) prepared by Al-Batsh and Abu Awad (2010).

\subsection{Literature Review}

Laboratory work is characterized by many advantages beyond the theoretical knowledge of facts and practical concepts, as practical experiences allow the student to use all his or her senses, abilities, motivation to succeed and to demonstrate his or her learning abilities (Kattom, 2016). Researchers in the field of scientific education and teaching science agreed that the practical study helps students to acquire information and skills, and the formation of scientific trends that serve the process of teaching science. Zeitoun (2007) stated that laboratory work gives the student an opportunity to learn through work, where students acquire practical sensory experience directly, and remember the scientific material for a long time. Scientific skills that students can acquire include: manual skills such as the use of laboratory tools, academic skills such as collecting and recording data, and the use of references. As well as social skills and communication, as in collective laboratory work and in student interactions, an addition to training on the skills of laboratory control, such as the arrangement of laboratory tools, cleaning and testing, as well as the acquisition of skills and processes of basic science and integrated and practice, as happens in observation, measurement, classification, prediction, inference and experimentation, in addition to establishing the love of work and the scientific approach in the minds of learners, the love of science and its means and tools, and the development of creative skills, such as planning, design, invention and installation skills

According to Al-Samerrai (2005), the modern philosophy of the laboratory emphasizes the need to prefer the practical side to the theoretical one to reach the theoretical knowledge that the student concluded. This means turning the role of the student into a positive one based on the conclusion and recording of the results and observations. Therefore, the laboratory is a way to stimulate the thinking of the student and motivate him or her to find solutions to existing problems, and raise new problems. It is a drive towards creativity and innovation that makes the educational process continuous and exciting.

Zeitoun (2004) noted that laboratory activities are not confined to the school but can be performed outside, provided that the learner participates in the activities under teacher supervision and assistance to enhance his or her motivation. Educators look at laboratory work with different views; while some believe that the laboratory is the home of science as a demonstration activity through which the teacher can prove the truth of scientific facts to students. Others see the laboratory as an inquiry, leaving the learner with the opportunity to do the activities himself. There are other types of laboratories such as the individual laboratory as the student conducts the experiment alone with the available tools and supplies. The group's laboratory divides learners into groups consisting of 5-8 students to conduct practical activities in a participatory manner, according to the prior coordination determined by the teacher. 
Due to the evolution of the role played by the laboratory in the teaching of science has become the most appropriate method of practice scientific method, academics (Zeitoun, 2013; Norman, Alderman, \& Antink, 2013; Adb-Khalick \& Akerson, 2005; Emine \& Salih, 2012) have mentioned in this regard that the scientific method and the necessary laboratories to practice it is a basic component of the nature of science, because of the close link between the concept of science and nature. Therefore, understanding the nature of science has educational implications that benefit both the teacher and the learner. This, of course, directs the research of literature into some of the components of the nature of science, as proposed by Dass (2005), like fields of science nature, scientific activity and knowledge, which focuses on the nature of scientific methods, the concept of scientific activity, and the scientific knowledge generated by this activity, in addition to knowing the conditions under which the scientists work, how they reach their conclusions, the social context of the scientific activity, community implications of the scientific activity, the educational implications, the use of scientific activity in the educational situations, and the application of the components of the nature of educational classroom situations, which requires the learner to understand the nature of science and scientific inquiry, and employing ethics of science in life.

Many educators emphasize the importance of integrating information and communication technologies into science education, in line with scientific progress and human development. The use of computers in the classroom is considered an important means of interaction. The concept of learning in the dry laboratory has emerged as an effective solution to overcome many of the gaps in the traditional educational patterns of science teaching in the scientific laboratories known as the wet labs (Al-Shnaq, Abu Hula, \& Al-Bawab, 2004). The dry lab is considered one of the applications of computer simulation programs where students have the opportunity to participate in learning through situations similar to the real situations they encounter in their daily lives. The abstract theoretical knowledge can be linked to the concrete application and students' understanding of concrete concepts. Reviewing the literature, the researchers adopted the following definition of dry laboratory: using computer software to carry out scientific activities by students through interaction with the computer so that the role of the teacher as an assistant.

The importance of the dry lab lies in the use of software and computer technologies in the classroom, providing lessons that develop learner self-learning and taking into account individual differences among students, encouraging students motivation towards learning, depending on the advantages offered by the computer such as sound, motion, attractive colors, and various simulation software (Baj Pai, 2013).

Thinking is seen as a necessary process in daily life. The individual's way of thinking relates to planning for life, goals and decisions. Thinking helps to distinguish between what one should do and what one can do. It helps to eliminate doubts by choosing from the available probabilities information, as well as increase the motivation of learners to learn and work (Al-Aysrah, 2011).

The views of scientists differed about the definition of thinking. Qatami (1990) defined thinking as a way of receiving, organizing, storing, recording and integrating knowledge into knowledge storage. Abu-Shamaleh (2006) defined it as a cognitive process that illustrates the relationships between things. It is a continuous series of mental activities and processes that the brain performs at the moment of exposure to a particular stimulus in order to obtain a result, resolution or solution to a problem.

Researchers agreed that thinking is a complex mental process consisting of a set of sub-mental processes. Examples of these processes are described by Omran (2009) include classification, organization, abstraction, generalization, concretization, analysis, and synthesis. Classification refers to the process of aggregating phenomena or events based on their common characteristics. The organization is the process of arrangement and coordination of phenomena in accordance with the relations between them. On the other hand, abstraction is defined as the process by which things are abstracted, which means excluding things that are not related to the present subject. Generalization is the mental process that is based on reaching the general principle of the phenomenon and applying this principle to other similar situations. association with the axioms refers to the transition from abstraction to generalization, such as striking examples inspired by the surrounding environment in order to grasp abstract concepts. Concretization refers to the transition from abstraction to generalization, such as giving examples of the surrounding environment in order to grasp abstract concepts. Analysis is defined as a mental process in which a whole phenomenon is divided into its partial components. Synthesis is the opposite of analysis, which means the unification of the phenomenon through the aggregation of its elements. The process enables a holistic concept of the phenomenon.

Saadeh (2003) clarified that teaching thinking skills to students leads to: help students to look at different issues from the perspective of others, accurately assess others' views, respect others' views, encourage students to answer 
difficult questions, provide solutions to complex problems, recognize the importance of teamwork, prepare students for practical life after school, and develop good citizenship. A review of educational philosophies indicates that the focus of these philosophies is on the development of the learner's mental skills, but the focus of schools on simple skills only, such as preservation and retrieval of information (Obiedat \& Abu Al-Semaid, 2005).

Thinking styles are many, varied and overlapping, and there are several labels describing one style of thinking such as logical thinking, critical or creative. Thinking style is defined as the way in which thinking is conducted based on the individual's culture, experience and mental abilities. Researchers (e.g., Al-Ustath, 2011; Al-Batsh \& Abu-Awad, 2010) pointed out that the reason for different thinking patterns is the difference of experiences, environments, cultures, interests, abilities, and neurons. Examples of thinking styles include: convergent, consequential, critical, analytical, logical, deductive, inductive, lateral, functional, mathematical, cognitive, creative, scientific, cognitive, strategic, systemic thinking.

Some studies indicated that the school laboratory raises the level of scientific and practical dignity of both teacher and student, and helps to provide a variety of sensory experiences that form the basis of understanding many facts, concepts, laws and practical applications (Shaheen \& Hattab, 2005). In a study by Al-Sharay and Abdul-Jabbar (2017), which aims to know the effect of using dry laboratory in the achievement of students in the third intermediate grade in science and the development of creative thinking skills in the province of Qurayat in Saudi Arabia. The study used the quasi-experimental method. The sample consisted of 44 students, who were divided into two groups of control and experimental groups. The study used an achievement test and a measure of creative thinking. The results of the study showed that there were statistically significant differences between the average achievement and creative thinking of the experimental group members who studied science using dry laboratory, the average achievement and creative thinking of the control group members studied in the usual way in favor of the experimental group.

Stern, Barnea and Shauil (2008) conducted a study aimed to assess the effect of using dry laboratory in simulating the theory of molecular motion on the understanding of seventh grade students of this theory. The study sample consisted of 133 seventh grade students in the United States of America. They were divided into two groups: a control group consisting of 62 students and a experimental group consisting of 71 students. The two groups received instruction on the different arrangement and movement of molecules in the three states of the material. The control group was studied using the traditional method and the experimental group was studied using the dry laboratory via simulation software. The results of the study showed that the experimental group scores were higher than the control group, and that the use of the dry laboratory improved the students' understanding of the theory of molecular motion.

Al-Reyahi's study (2016) aimed to identify the effect of Postlethwaite method in the acquisition of laboratory skills and the development of mental processes in the students of the basic stage with different logical thinking. The sample of the study consisted of 72 female students of the ninth grade in a school of the Directorate of Education of the University District in the capital city, Amman. The study used three tools: the laboratory skills observation standard, the mental processes test, and the logical thinking test. The study found that the method of teaching using Postlethwaite was superior to the traditional method of acquiring laboratory skills. It also found an effect on the interaction between Postlethwaite method and logical thinking in the development of mental processes, and the absence of interaction between teaching method and logical thinking in the development of mental processes.

Abu Zant (2015) conducted a study aimed at finding out the effect of using the virtual lab on the development of laboratory skills and attitudes towards its use in physics learning among physics students at the Faculty of Science at Al-Najah National University in Nablus, Palestine. The sample consisted of 54 students distributed in two control groups studied in the traditional and experimental way studied by default. The study found differences between the two groups due to the teaching method for the experimental group.

Al-Musawi, Ambusaidi, Al-Balushi and Al-Bakushi (2015) conducted a study to measure the effectiveness of the electronic laboratory in teaching science in the acquisition of abilities and practical skills in laboratory work by students of basic education in Amman for. The study also aimed to know the students' attitudes toward using and employing electronic lab technology. The study sample consisted of 42 students divided into experimental and control groups. The laboratory skills and attitudes scale were used. The study found differences between the two groups in the laboratory skills test and attitudes scale for the experimental group studied by electronic laboratory.

The interactive training has received considerable attention from researchers because of its positive results. As the teacher is the most one who capable of designing programs for interactive training, educators have given great attention to developing teaching methods to help students master skills, including practical skills. Therefore, the current study was conducted to examine the effect of the interactive drills using the dry laboratory to acquire 
laboratory skills in the science by the ninth grad female students in Palestine in the light of their thinking styles.

\section{Method}

The quasi-experimental method was used to identify the effect of the interactive drills using the dry laboratory in the acquisition of laboratory skills in the science of the ninth-grade female students in Palestine in light of their styles of thinking of using pre and post-test measurement of the experimental and control groups, because this approach fits the study and its purpose.

\subsection{Study Sample}

Barakat Primary School was chosen purposively, a public school of the Directorate of Education and Hebron in Palestine, and this was because the school is close to the researcher's residence, the availability of computer labs and the cooperation of the school principal. The thinking test was applied to all ninth-grade students in the school. There were 156 female students distributed on 4 sections. After the results are sorted, according to the following equation: arithmetic mean - arithmetic mean/standard deviation, showing the achievement of the criterion used to determine the level of thinking style, depending on the distance of the mark from the standard deviation. Where the result is greater than or equal to 1 be a concrete or abstract thinking based on the raw degree. The test has been matched to 68 female students. This number was divided into 2 section with 34 female students per section, half of the section was of concrete thinking and the other half of abstract thinking. Both experimental and control groups were randomly assigned. Table 1 shows the distribution of study participants.

Table 1. Participants distribution based on teaching method and thinking style

\begin{tabular}{llll}
\hline & Concrete thinking & Abstract thinking & Total \\
\hline Experimental & 17 & 17 & 34 \\
Control & 17 & 17 & 34 \\
Total & 34 & 34 & 68 \\
\hline
\end{tabular}

\subsection{Study Instruments}

\subsubsection{Test of Situations to Measure Laboratory Skills}

The researcher prepared a test of situations in order to measure the skills of laboratory work, after reviewing the educational literature (Dar Ibrahim, 2014), and the document of educational evaluation for the science of the ninth grade, where the situation is presented to the student and the teacher asked several questions related to the practical skills of each skill. The initial test consists of 4 situations and 15 questions of multiple-choice type, and is designed to measure the following laboratory skills: pre-experiment skills, including readiness, preparedness, observation, and skills during the experiment, including measurement and classification, safety considerations and others. Skills after the experiment include: conclusion, assessment and reporting.

a. Validity: The validity of the content was confirmed by presenting the test in its preliminary form to a group of specialists in curriculum and teaching methods, educational evaluation, and educational supervisors, in order to read the test, provide observations on language and the relevance of the questions. The inappropriate items were deleted and the situations and questions were redrafted. The final version of the test contains 15 questions.

b. Reliability: Reliability was investigated using tested and re-test. The test was applied on 47 students from outside the study sample. The test was re-applied after 14-day interval. The Pearson correlation coefficient was calculated (0.81). The internal consistency coefficient was calculated according to the Cranach's Alpha formula and reached (0.91). This means that the test of laboratory skills had a high degree of reliability.

\subsubsection{Test of Thinking Styles}

The test of thinking styles (concrete and abstract) developed by Al-Batsh and Abu Awad (2010) was used to identify outstanding students in Jordan for enrolling them in King Abdullah Schools of Excellence. The test, in addition to the thinking tests, includes tests of cognitive abilities, personality traits and test for mathematics, Arabic, English and science. The test of concrete thinking consists of 42 items, each item consists of two associated words, the respondent was asked to examine the two words and reveal the relationship between them, and choose one of the four alternatives, which includes a pair of words that have the same relationship. The abstract thinking test consists of 29 items, each item contains a pair of shapes connected together to a certain base and another shape beside the space. The respondent is asked to examine the shapes in the item and discover the relationship between them, then to choose a pair of shapes from the choices, along with the item with the same relation with the third shape in the body of the question. 


\subsection{Study Variables}

\section{Independent variables}

Teaching Method: Interactive drills using dry laboratory, and the usual method.

Thinking style (categorical variable): concrete and abstract thinking

Dependent variable: laboratory skills.

\section{Results}

\subsection{Results of the First Question}

Means and standard deviations (SD) of the performance of the two study groups were calculated on the post-test of scientific concepts (control group and experimental), and patterns of thinking in tribal and post-application, as shown in Table 2.

Table 2. Means and standard deviations of lab skills test (pre and post) based on teaching method and thinking style

\begin{tabular}{lllllll}
\hline Teaching method & Thinking style & Number & \multicolumn{2}{c}{ pre-test of lab skills } & \multicolumn{2}{c}{ post-test of lab skills } \\
\cline { 5 - 7 } & & & Mean & SD & Mean & SD \\
\hline Interactive drills via dry lab (experimental) & concrete & 17 & 7.41 & 1.62 & 13.47 & 2.12 \\
& abstract & 17 & 6.76 & 1.68 & 29.14 & 1.21 \\
& Total & 34 & 7.09 & 1.66 & 13.88 & 1.75 \\
Traditional (control group) & concrete & 17 & 7.24 & 1.86 & 10.35 & 2.55 \\
& abstract & 17 & 6.76 & 1.75 & 9.41 & 1.66 \\
Total & Total & 34 & 7.00 & 1.79 & 9.88 & 2.17 \\
& concrete & 34 & 7.33 & 1.72 & 11.91 & 2.80 \\
& abstract & 34 & 6.76 & 1.69 & 11.85 & 2.86 \\
\hline
\end{tabular}

Table 2 shows a difference between the means and the standard deviations of female students' scores in pre and post-laboratory skills test between the two groups according to thinking style. Pre-mean of students with concrete thinking (7.33) and the standard deviation (1.72), while the mean of the students' grades with abstract thinking (6.76) and standard deviation (1.69). On the other hand, mean scores of students in the experimental group who studied the interactive training method using the dry laboratory (mean $=7.09, \mathrm{SD}=1.66$ ), and means of the students of the control group who studied in the traditional method (7.00) and standard deviation (1.79).

In terms of post-skill test results, it was found that for the results of the skills test, the mean score of the concrete thinking in the post-laboratory skills test (11.91) and the standard deviation (2.80). The mean score of the abstract thinking (11.85) and the standard deviation (2.86). On the other hand, the mean score of the experimental group (13.88) and the standard deviation (1.75) compared to the mean of control group (9.88) and standard deviation (2.17). In order to detect the significance of the differences, a two-way ANCOVA was conducted for the effect of teaching method and thinking style and interaction between them in the acquisition of laboratory skills, as shown in Table (3).

Table 3. Two-way ANCOVA of differences significance of lab skills test based on teaching method and thinking style

\begin{tabular}{lllllll}
\hline variance source & sum of squares & degrees of freedom & mean square & F & Sig. & (Partial) Eta Squared \\
\hline lab skills pre-test & 80.531 & 1 & 80.531 & 31.081 & 0.000 & 0.330 \\
method & 264.087 & 1 & 264.087 & 101.925 & 0.000 & 0.618 \\
method*thinking style & 16.483 & 2 & 8.242 & 3.181 & 0.048 & 0.092 \\
error & 163.233 & 63 & 2.591 & & & \\
total & 529.059 & 67 & & & & \\
\hline
\end{tabular}

Table 3 shows that there is a statistically significant difference between the experimental and control groups $(\mathrm{F}=$ $101.925)$ at the significance level (0.05) in favor of the experimental group. The adjusted mean of the experimental group (13.85) and the control group (9.91). This indicates that teaching using interactive drills using the dry laboratory contributed to the development of the laboratory skills of the students.

It is clear from Table (3) that the magnitude of the effect (measured by the partial ETA) of the teaching method in the laboratory skills is $(0.618)$, i.e., the use of interactive drills using dry laboratory explains $(61.8 \%)$ of the total 
variance in laboratory skills. This effect is classified as moderate (Cohen, 1988).

\subsection{Results of the Second Question}

Table 3 shows statistically significant differences in laboratory skills due to the interaction between the teaching of the experimental and control groups $(\mathrm{F}=3.181$, Sig. $=0.048)$. This means that there is an impact of the teaching method using interactive drills on the development of laboratory skills in the ninth grade. Table 4 shows the values of the post-laboratory means after the elimination of the effect of the pretest.

Table 4. Adjusted means and standard deviations of lab skills test for experimental and control groups

\begin{tabular}{llll}
\hline Teaching method & Thinking style & Adjusted post mean & standardized error \\
\cline { 3 - 4 } & & Mean & SD \\
\hline Interactive drills via dry lab (experimental) & Concrete & 13.23 & 0.39 \\
& abstract & 14.47 & 0.39 \\
& Total & 13.85 & 0.27 \\
Traditional (control group) & concrete & 10.22 & 0.39 \\
& abstract & 9.59 & 0.39 \\
& Total & 9.91 & 0.27 \\
\hline
\end{tabular}

\section{Discussion}

\subsection{Discussion of the First Question}

Results of statistical analysis There is a significant and real difference between the experimental and control groups in the post-test of laboratory skills. If this process indicated the superiority of the method of using interactive exercises. The dry laboratory allows the student to experiment without the supervision of the teacher and to identify the lab equipment and tools. At any time without adhering to certain limits of experience, proposing work and using alternative tools, and dealing with devices not available in traditional laboratories.

Qatoum (2016) emphasized the advantages of laboratory work. She pointed out that laboratory work has advantages beyond theoretical knowledge, but also the use of senses, competencies and scientific abilities. This increased students' acquisition of laboratory skills. In the opinion of the researchers that the good planning for the design of interactive drills have contributed to the acquisition of laboratory skills, as the activities and interactive attitudes are designed so that the student is the focus of the educational process, and is the biggest burden in the process of learning by thinking of the problem and propose solutions and identify sources, which in turn increases the acquisition of laboratory skills.

The researchers attributed the superiority of the experimental group students to the students of the control group in the level of acquisition of laboratory skills to the effective role of the students in the experimental group, linking the information to the life situations contained in the courses and the activities carried out in the dry laboratory, which increases the self-confidence of the student and thus the development of work skills Laboratory. This result is consistent with the results Qatoum (2016), which showed statistically significant differences between the means of the experimental group and the control group in laboratory skills test in favor of the experimental group. In addition to Al-Rihi's study (2016) that showed a statistically significant between the averages of the scores of the students of the experimental group and control in the test of laboratory skills according to the teaching method in favor of the experimental group. As well, the result was in agreement with agreed with the Abu Zant study (2015) who indicated that that there were statistically significant differences between the mean of the experimental group and the mean of the students of the control group in the laboratory skills test in favor of the students of the experimental group who conducted the experiments in the virtual laboratory. And with the results of Al-Moussawi study (2015) which showed that there were statistically significant differences between the average scores of the two groups in the laboratory skills test and the trend scale where the difference was in favor of the experimental group studied in the electronic laboratory method.

\subsection{Discussion of the Second Question}

The results of the statistical analysis showed an interaction between the method of teaching (the interactive exercises in the dry laboratory, traditional) and the patterns of thinking (physical, abstract) in the acquisition of laboratory skills in the science of the ninth graders in Palestine. The arithmetic mean of the group's abstract-thinking group performance was higher than the arithmetical mean of the group's performance of the physical thinking pattern. This result can be explained by the strong relationship between laboratory skills and thinking style. The pattern of thinking includes a variety of skills such as the skill of determining the assignment 
and the assumption of hypotheses. This result is also due to the relationship between the thinking style and the teaching method used in the current study Dry Lab. Students with abstract thinking have the ability to organize the learning process in logical steps, taking into account the assessment of each step. Emphasis has been placed on students' abilities and work on their development using a modern teaching method that focuses on self-motivation in learning. Students with abstract thinking are more appropriate to learn in the interactive training method using a dry laboratory that fits the thinking style. This has enhanced students' sense of responsibility for learning and has led to the acquisition of laboratory skills through positive interaction with procedural steps that correspond to the scientific method. Thinking, questioning, clarifying and clarifying ambiguity about the scientific material in order to arrive at explanations through the process of summarizing and feedback.

\section{- Recommendations}

In the light of the findings of the study, the researchers provide the following recommendations:

1) Using the interactive drills method in the dry laboratory for teaching the ninth-grade students in Palestine in light of the outcomes of learning laboratory skills

2) Using the interactive drills method in the dry laboratory in light of the difference in the thinking styles in the case of laboratory skills

3) Conducting comparative studies through the use of new variables that not used in the current study, and discuss the obstacles of using the interactive drills in the dry laboratory in the educational process in different stages of study.

\section{Study Limitations}

Human limitations: The study was applied on the ninth-grade female students.

Spatial limitations: Barakat Elementary School of the Education Directorate in Hebron, Palestine.

Time limitations: Second Semester 2017-2018.

Objective Limitations: The study was limited to the fourth unit in the book of science, which is concerned with chemical equations, bonds, and types of interactions. The results of the study shall be determined based on the sample and the tools used and their Psychometric characteristics.

\section{References}

Abd-El-Khalick, F., \& Akreson, V. (2005). How should I know what scientists do? I am just a kid: Fourth-Grade student's conceptions of nature of science. Journal of Elementary Science Education, 17(11), 1-110

Abu Shammaleh, F. (2006). The effectiveness of a proposed program in acquiring the physical structure of the Ninth-Grade students in Gaza Governorate. PhD Dissertation Dissertation, Ain Shams University, Egypt.

Abu Zant, L. (2015). The effect of using the virtual laboratory on the development of laboratory skills and trends towards its use in physics learning among the students of physics department at the Faculty of Science at An-Najah National University. Unpublished MA, An-Najah National University, Nablus, Palestine.

Al-Ayasra, W. (2011). Critical Thinking and its Teaching Strategies. Amman: Dar Osama for Publishing.

Al-Bashaireh, Z. A., \& Al-Obaideen, M. Z. (2014). Effect of teaching methods of laboratory work in the achievement of laboratory skills for secondary students in chemistry in Jordan. Journal of the Union of Arab Universities for Education and Psychology, 12(2), 95-114.

Al-Batsh, M. W., \& Abu Awad, F. (2010). Test concrete thinking, abstract. Battery tests to detect outstanding students in Jordan to enroll in King Abdullah School of Excellence. Amman: Ministry of Education.

Al-Hadabi, D., \& Al-Makhlafi, M. (2009). Level of mastery of the fourth level students at the Faculty of Education Sana'a University for the laboratory skills required to teach physics in the secondary stage. The Arab Journal for Quality Assurance of University Education, 2(4), 51-91.

Ali, M., Zakaria, M., \& Salim, N. (2010). The effect of using transparencies and illustrations to provide conceptual mapping technology in the achievement and acquisition of laboratory skills for students of the chemistry department at the Faculty of Education at the University of Mosul. Journal of Education and Science, 17(1), 246-269.

Al Musawi, S., Ambusaidi, N., AL- Balushi, D., \& AL- Balushi, H. (2015). The effectiveness of the electronic laboratory in teaching science in the acquisition of basic education students in Oman for abilities, practical skills and skills acquisition. Journal of Educational Technology, 12(5), 61-88. 
Al-Najdi, A., Abdulhadi, M., \& Rashid, A. (2002). Modern methods and strategies in teaching science. Cairo: Arab Thought House.

Al-Reyahi, S. (2016). The effect of Postlethwaite method on the acquisition of laboratory skills and the development of mental processes among students of the basic stage with different logical thinking. Dirasat Journal, Educational Sciences, 43, 871-887. https://doi.org/10.12816/0033597

Al-Sammeraee, N. (2005). Fundamentals of Teaching Science: Modern Trends. Amman: Al-Ukhwah for publication.

Al-Sharari, S., \& Abdul-Jabbar, S. (2017). The effect of dry lab in the achievement of students in the intermediate third grade in science and the development of creative thinking skills in the province of Qurayat. Journal of Studies, Educational Sciences, 44(4), 195-221.

Al-Sherida, M., \& Bishara, M. (2010). Complex Thinking and its Relation to Some Variables: A Field Study on the Students of Al - Hussein Bin Talal University. Damascus Journal, 26(3), 217-552.

Al-Shunak, Q., Abu Hula, M., \& Al-Bawab, A. (2004). Effect of using the dry lab strategy in the achievement of science students at the University of Jordan. Journal of Dirasr, Educational Sciences, 1(3), 317-338.

Al-Soub, T. (2007). The Effect of Using Dry Lab in Teaching Chemistry in Acquiring Skills of Basic and Integrated Science Operations for First Grade Students in Saudi Arabia. Unpublished Master Thesis, Mu'tah University, Jordan.

Al-Tarawneh, S., \& Al-Qudah, A. (2014). The relationship between seduction resistance and prevailing thinking styles among university students. The Jordanian Journal of Educational Sciences, 10(1), 89-100.

Aram, M. (2012). The impact of the KWL strategy on the acquisition of concepts and critical thinking skills in science among the seventh-grade students. Unpublished master thesis, Islamic University, Gaza, Palestine.

Attiyat, M. (2013). Styles of thinking in the light of the Sternberg model in the students of Balqa Applied University and its relation to some variables. Dirasat, Educational Sciences, 40(3), 1135-1159.

BajPai, M. (2013). Developing concepts in Physics through virtual lab Experiment: An Effectiveness study. American international Journal of Contemporary Research, 4(3), 201-244.

Cohen, J. (1988). Statistical power analysis for the behavioral sciences. Hillslal, NJ: Erlbaum

Dar Ibrahim, Y. (2014). The use of the virtual laboratory for science experiments in the development of science processes and acquisition of concepts among fifth grade students in Palestine. Unpublished master thesis, An-Najah National University, Nablus, Palestine.

Dass, P. (2005). Understanding the Nature of scientific enterprise (Noest) through a discourse with its history: The influence of an under graduate history of science course. International Journal of Science and Mathematics Education, 3, 87-45. https://doi.org/10.1007/s10763-004-3225-1

Emine, C., \& Salih, C. (2012). The effeteness of the conceptual change Approach, Explicit Reflective Approach, and course Book by the ministry of education on the Views of Nature of science and conceptual in light unit. Educational Science: Theory and Practice, 12(2), 1107-1113

Norman, G., Aldermen, S., \& Antink, A. (2013). Nature of science and scientific inquiry as contexts for learning of science and achievement of scientific literacy. International Journal of Education in Mathematics, Science and Technology (IJEMST), 1(3), 138-147.

.Jamal, M., \& Al-Hawidi, Z. (2003). Methods of detection of creative and talented and the development of thinking and creativity. Al Ain: University Book House.

Mohammed, A. (2007). Effectiveness of the virtual work in the achievement of different levels of secondary students in chemistry course. Unpublished master thesis, Taibah University, Medina, Saudi Arabia.

Nabhan, S. (2001). A proposed program for the development of critical thinking in mathematics for ninth grade students in Gaza. PhD Dissertation, Ain Shams University, joint graduate program with the Faculty of Education in Gaza, Palestine.

Obaidat, T., \& Abu Samaid, S. (2005). Brain, Learning and Thinking (2nd ed.). Amman: Dibono for Printing, Publishing and Distribution.

Omran, M. (2009). Introduction to Psychology. Cairo: Student Services Library.

Palestinian Central Bureau of Statistics. (2011). Annual Report, Palestine Children. Issues and Statistics, Child 
Statistics Series, 15, Ramallah, Palestine.

Qatami, N. (1990). Teaching thinking of the basic stage. Amman: Dar Al Fikr for Publishing and Distribution.

Qatoum, R. (2016). The effect of using the method of laboratory work in the performance of first year students at Jerash University in chemistry laboratories and acquisition of laboratory skills. Unpublished Master Thesis, Jerash University, Jordan.

Saadeh, G. (2003). Teaching Thinking Skills (1st ed.). Amman: Dar Al Shorouk Publishing \& Distribution.

Salah Abdul Mohsen Ajaj Educational Blog. (2014). The Dry Lab, an educational blog concerned with the development of educational curricula, educational materials and teacher training. Retrieved from http://www.dr-salahagag.blogspot.com

Shahin, J., \& Hattab, K. (2005). The school laboratory and its role in teaching science. Amman: Dar-el-Usrah for publishing.

Stern, A., Barnea, H., \& Shauli, V. (2008). Evaluation of the impact of dry laboratory use in simulating molecular motion theory on students' understanding. Science Educator, 3(2), 36-58.

Ustath, M. (2011). The level of thinking ability of science teachers in the basic stage in Gaza. Journal of Al-Azhar University, 13(1), 1329-1370.

Zeitoun, A. (2004). Methods of Teaching Science (1st ed.). Amman: Dar Al Shorouk for Publishing and Distribution.

Zeitoun, A. (2007). Methods of Teaching Science (5th ed.). Amman: Dar Al Shorouk for Publishing and Distribution.

Zeitoun, A. (2007a). Structural theory and science teaching strategies. Amman: Dar Al for Shorouk Publishing \& Distribution.

Zeitoun, A. (2013). The level of understanding of the nature of the scientific endeavor in the light of Project 2016 among science teachers in Jordan and its relation to some demographic variables. Jordanian Journal of Educational Sciences, 9(2), 119-139.

\section{Copyrights}

Copyright for this article is retained by the author, with first publication rights granted to the journal.

This is an open-access article distributed under the terms and conditions of the Creative Commons Attribution license (http://creativecommons.org/licenses/by/4.0/). 